\title{
PENGGUNAAN PANCING LINGKAR (CIRCLE HOOK) PADA RAWAI TUNA (TUNA LONG LINE) UNTUK MENGURANGI HASIL TANGKAPAN PENYU DI PERAIRAN SELATAN BALI
}

\author{
Sawon \\ Teknisi Litkayasa pada Balai Riset Perikanan Laut, Muara Baru-Jakarta \\ Teregistrasi I tanggal: 23 Juli 2008; Diterima setelah perbaikan tanggal: 24 Juli 2008; \\ Disetujui terbit tanggal: 25 Juli 2008
}

\section{PENDAHULUAN}

Penggunaan pancing lingkar (circle hook) tidak menurunkan hasil tangkapan secara signifikan, sedangkan burung laut dan mamalia laut sangat sedikit berinteraksi dengan rawai tuna di perairan Indonesia. Semakin langka populasi hewan yang dilindungi bukan saja di darat, di laut pun demikian. Penangkapan secara liar atau tak terkendali menjadi penyebab dari kepunahan satwa langka. Hewan yang dilindungi antara lain, mamalia laut sejenis lumba-lumba, hiu, penyu, paus, burung laut, dan lain-lain.

Benoa yang merupakan bagian dari Propinsi Bali secara geografis, terletak pada posisi $08^{\circ} 51^{\prime}$ LS dan $115^{\circ} 12^{\prime}$ BT. Perairan Benoa Bali, merupakan salah satu wilayah penyebaran jenis-jenis ikan pelagis dan demersal, seperti ikan layang (Decapterus spp.), lemuru (Sardinella longiceps), cakalang (Katsuwonus pelamis), madidihang (Thunnus albacares), kakap merah (Lutjanus spp.), dan kurisi (Nemipterus spp.). Ikan-ikan tersebut merupakan hasil tangkapan utama di wilayah lepas pantai (off shore), khususnya di perairan Pejantan (dekat Pulau Nusa Penida).

Salah satu jenis pancing yang dioperasikan pada rawai tuna di perairan Benoa Bali adalah pancing lingkar (circle hook). Pancing lingkar (circle hook) dioperasikan secara bersamaan dengan jenis pancing konvensional yaitu Japanese tuna hook (J-hook). Jenis pancing ini ditujukan untuk mengurangi tangkapan penyu yang merupakan hewan yang dilindungi.

Respon positif, Balai Riset Perikanan Laut bekerja sama dengan World Wild Fund, telah mengembangkan alat tangkap pancing yang ramah lingkungan yaitu circle hook atau pancing lingkar yang dapat mengurangi bycatch penyu dan mempermudah melepaskan ketika terjerat oleh alat tangkap tersebut karena kemiringan atau lingkaran $5^{\circ}$ (Merta, 2004). Sebelumnya alat tangkap pancing yang digunakan oleh kapal-kapal long line adalah jenis J-hook, alat tangkap serupa namun kurang ramah lingkungan (IATTC, 1999).

Ada 4 jenis alat pancing lingkar ini yakni type $C 14 /$ 0, C15/0, C16/0, dan C18/0. Berdasarkan pada hasil uji coba di Bitung, Sulawesi Utara, Cilacap, Jawa
Tengah, dan Benoa, Bali jenis C16/0 yang cocok untuk dipakai oleh semua kapal long line.

Tujuan penulisan ini adalah menyajikan data dan informasi mengenai karakteristik pancing jenis circle hook, aspek operasional, dan efektivitas dalam mengurangi hasil tangkapan penyu. Penelitian dilakukan terhadap pancing $C$-hook dan J-hook yang dioperasikan menggunakan kapal motor milik nelayan setempat.

\section{DAERAH PENANGKAPAN}

Daerah penangkapan ikan pelagis besar dan ikan demersal tersebar dari jarak $04-07^{\circ} \mathrm{LS}$ dan $124-132^{\circ}$ BT dari Pantai Benoa Bali. Lokasi perikanan dengan alat bantu rumpon laut dalam terdapat di selatan Bali. Pemasangan alat bantu rumpon bertujuan untuk mengumpulkan ikan supaya jarak tempuh melaut tidak terlalu jauh, dan menghemat bahan bakar minyak. Pengoperasian pancing $C$-hook dan J-hook berada di luar rumpon, dengan jumlah rata-rata setiap kapal 1.200-1.500 mata pancing dengan menggunakan umpan ikan layang dan lemuru (Gambar 1).

\section{DESKRIPSI KAPAL DAN ALAT TANGKAP}

\section{Kapal}

Kapal yang dioperasikan dengan alat tangkap pancing C-hook dan J-hook adalah kapal kayu dibuat oleh galangan kapal di Banyuwangi Jawa Timur antara tahun 2004-2007. Dengan ukuran panjang (LOA) 25,18 $\mathrm{m}$; lebar (W) 7,32 m; dalam (D) 2,70 m, dan bobot kotor 120 GT, mesin Yanmar 380 PK, dengan kecepatan 7,5 knot. Pancing ditarik dengan alat bantu line hauler berkisar antara 11-13 jam. Lama melaut 24-36 hari, dan kapal ini diawaki oleh 15 orang anak buah kapal, yang terdiri atas 1 orang nahkoda kapal, 1 orang koki, dan 13 orang pemancing (Tabel 1).

\section{Desain Alat Tangkap}

Dimensi tiap unit pancing $C$-hook dan J-hook di Benoa Bali secara umum terbagi dalam 4 bagian utama yaitu tali utama (mainline) monofilament $3 \mathrm{~mm}$, panjang $101,250 \mathrm{~m}$, tali cabang (branchline) kuralon $4 \mathrm{~mm}$, panjang $0,70 \mathrm{~m}$ dan monofilament $2 \mathrm{~mm}$ 
panjang $25 \mathrm{~m}$. Tali pelampung PE $4 \mathrm{~mm}$ panjang 25 $\mathrm{m}$ dan tali selambar PE $8 \mathrm{~mm}$ panjang $50 \mathrm{~m}$, mata pancing ukuran C-hook C16/0 dan pancing J-hook no.6, dan jarak antar pancing $67,5 \mathrm{~m}$. Setiap kapal terdiri atas 1.200-1.500 mata (Gambar 2).

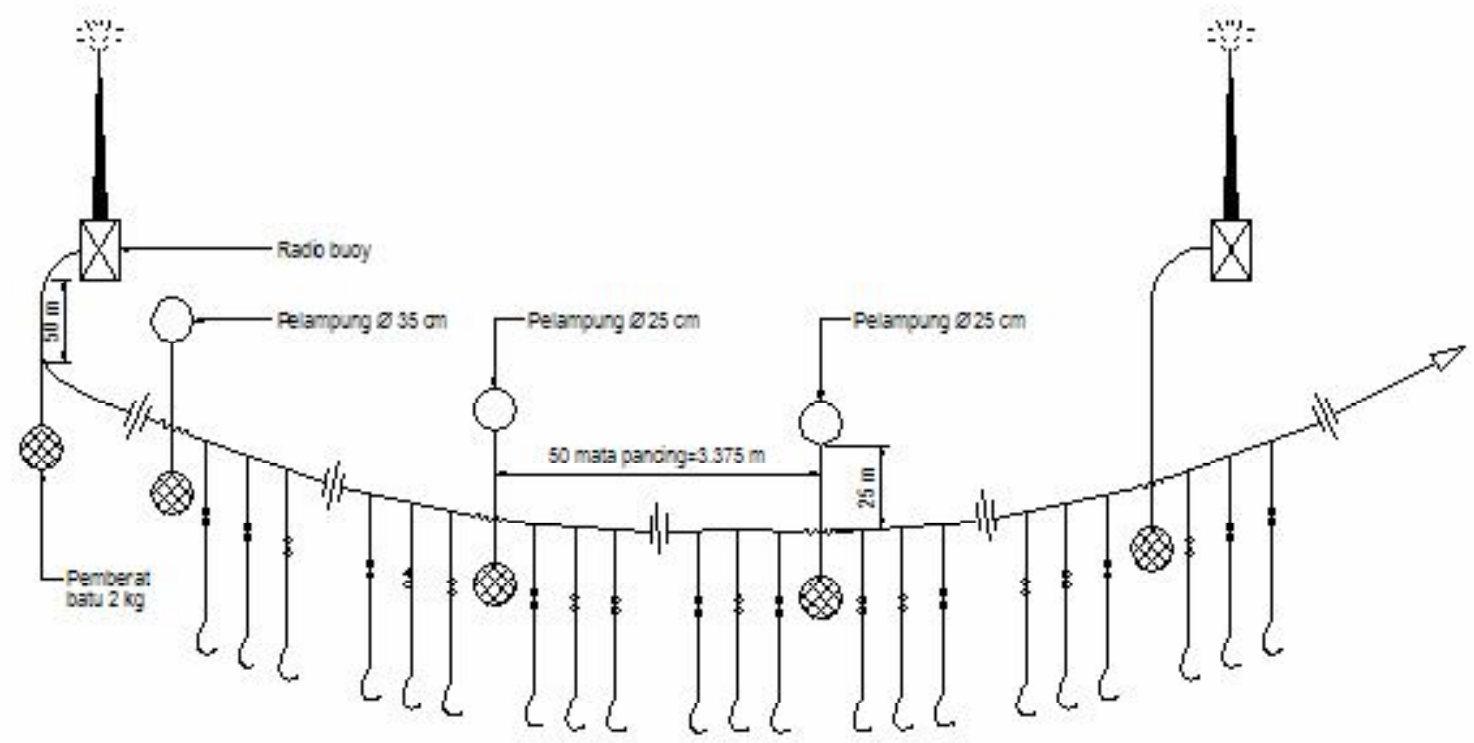

Gambar Rancang bangun dan konstruksi pancing long line

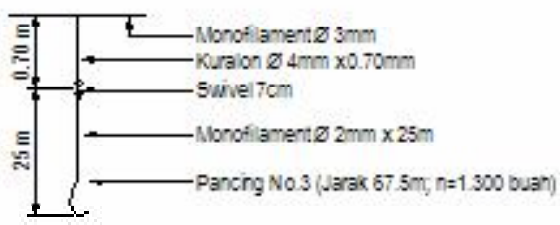

Gambar 1. Desain pancing C-hook dan J-hook.

Tabel 1. Spesifikasi kapal pancing C-hook dan J-hook di Benoa Bali, bulan Desember 2007

\begin{tabular}{|c|c|c|c|c|c|c|c|}
\hline \multirow{2}{*}{ No. } & \multirow{2}{*}{ Nama kapal } & \multicolumn{3}{|c|}{ Ukuran (m) } & \multirow{2}{*}{ GT } & \multirow{2}{*}{ Mesin (PK) } & \multirow{2}{*}{ Alat/pancing } \\
\hline & & LOA & $\mathbf{W}$ & D & & & \\
\hline 1. & KM. Bali Permai 169 & 25,18 & 7,32 & 2,70 & 120 & 380 & C-hooks-J-hooks \\
\hline 2. & KM. Samudera 31 & 22,15 & 5,90 & 1,95 & 74 & 240 & C-hooks-J-hooks \\
\hline 3. & KM. Samudera 45 & 16,20 & 4,50 & 2,20 & 60 & 240 & C-hooks-J-hooks \\
\hline 4. & KM. Samudera 42 & 16,20 & 4,20 & 2,20 & 64 & 270 & C-hooks-J-hooks \\
\hline 5. & KM. Samudera 33 & 23,06 & 6,24 & 1,99 & 79 & 300 & C-hooks-J-hooks \\
\hline 6. & KM. Samudera 30 & 18,80 & 5,50 & 1,87 & 70 & 240 & C-hooks-J-hooks \\
\hline 7. & KM. Samudera 37 & 21,50 & 5,20 & 2,20 & 74 & 240 & C-hooks-J-hooks \\
\hline 8. & KM. Sari Segara 01 & 16,66 & 3,65 & 1,55 & 64 & 280 & C-hooks-J-hooks \\
\hline 9. & KM. Maju Setia VI & 24,60 & 6,60 & 1,98 & 88 & 350 & C-hooks-J-hooks \\
\hline 10. & KM. Dahlia & 24,70 & 6,90 & 2,00 & 90 & 350 & C-hooks-J-hooks \\
\hline
\end{tabular}

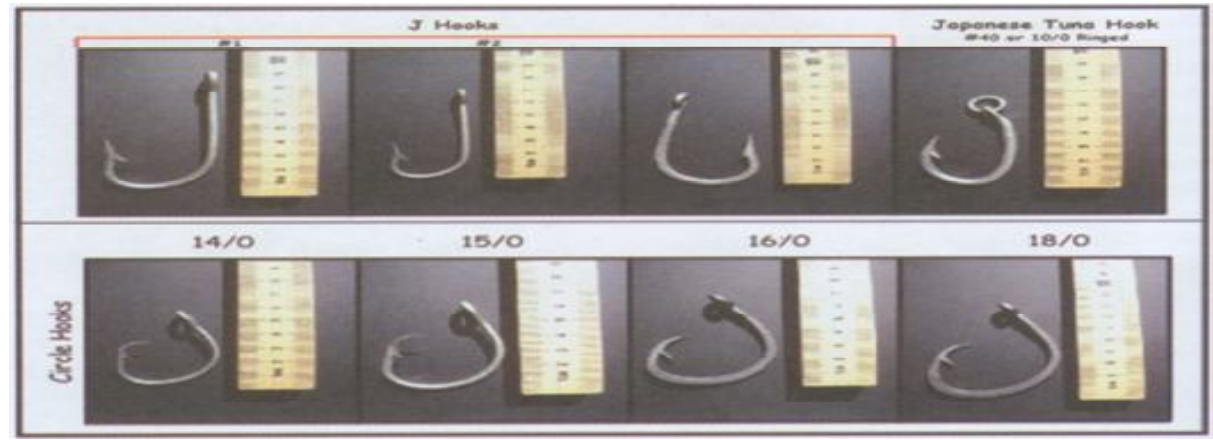

Gambar 2. Pancing C-hook dan J-hook. 


\section{Cara Pengoperasian Alat}

1. Pengoperasian pancing C-hook dan J-hook dilakukan secara bersamaan dengan kapal motor dari kayu berukuran panjang 25,18 $\mathrm{m}$, lebar 7,32 $\mathrm{m}$, dalam 2,70 m, dan bobot kotor $120 \mathrm{GT}$.

2. Pengoperasian pancing C-hook dan J-hook dilakukan dengan sistem kotak, artinya posisi arah pancing pertama sampai yang terakhir tidak searah, namun pada setiap 9 basket posisi kapal berbelok ke kanan sampai 9 basket berikut sehingga membentuk kotak, dan dari pancing terakhir kapal menuju pancing pertama untuk melakukan penarikan (haulling).

3. Penurunan pancing (setting) dilakukan setiap kapal sampai dengan pada posisi yang dituju, tidak tergantung waktu dan jam baik malam maupun siang hari.

4. Lama penurunan (setting) berkisar antara 6-7 jam.

5. Penarikan (haulling) dimulai dari pancing yang diturunkan pertama, menggunakan alat bantu line hauler dan lama penarikan berkisar antara 11-13 jam.

6. Pada setiap 1 basket (50 mata pancing) panjang $3,375 \mathrm{~m}$ dipasang 1 buah pelampung diameter 35 $\mathrm{cm}$ dan 9 buah pelampung diameter $25 \mathrm{~cm}$.
7. Pada setiap 3 basket ( 150 mata pancing) panjang $10,125 \mathrm{~m}$ dipasang 2 buah pelampung diameter $35 \mathrm{~cm}, 27$ pelampung diameter $25 \mathrm{~cm}$, dan 1 buah radio bouy yang dilengkapi bendera dan lampu kelip.

8. Pemberat timah @ 2,0 kg dipasang pada setiap basket (50 mata pancing) 1 buah, jumlah keseluruhan $=27$ buah.

9. Umpan yang digunakan adalah layang (Decapterus russelli) dan lemuru (Sardinella longiceps).

10. Pengemasan ikan hasil tangkapan dilakukan dengan cara memasukkan dalam palkah berisolasi dan diberi es balok.

\section{Hasil Tangkapan Penyu}

Keampuhan dan keefektifan alat tangkap ini sudah dirasakan oleh sebagian para nelayan tuna long line. Uji coba yang dilakukan di Benoa, Bali oleh 10 kapal hasil tangkapan pancing lingkar ( $C$-hook) lebih unggul dalam menagkap tuna 8,15\%. Dan memberikan hasil sangat signifikan dalam mengurangi bycatch penyu dari rata-rata 10-15 ekor menjadi 2-5 ekor atau mengurangi $67,27 \%$ setiap 40 hari penangkapan (Tabel 2 dan 3).

Tabel 2. Perbandingan hasil tangkapan ikan antara pancing C-hook dan J-hook dari 10 kapal di perairan selatan Bali, bulan Desember 2007

\begin{tabular}{clcc}
\hline & Nama kapal & \multicolumn{2}{c}{ Hasil tangkapan ikan } \\
\cline { 3 - 4 } No. & & C-hook (ekor) & J-hook (ekor) \\
\hline 1. & KM. Bali Permai 169 & 741 & 612 \\
2. & KM. Samudera 31 & 160 & 183 \\
3. & KM. Samudera 45 & 235 & 112 \\
4. & KM. Samudera 42 & 109 & 102 \\
5. & KM. Samudera 33 & 86 & 98 \\
6. & KM. Samudera 30 & 87 & 52 \\
7. & KM. Samudera 37 & 254 & 199 \\
8. & KM. Sari Segara 01 & 485 & 384 \\
9. & KM. Maju Setia VI & 243 & 285 \\
10. & KM. Dahlia & 186 & 169 \\
\hline
\end{tabular}

Sumber: Hasil wawancara dengan nahkoda kapal

Tabel 3. Perbandingan hasil tangkapan penyu antara pancing $C$-hook dan $J$-hook dari 10 kapal di perairan selatan Bali, bulan Desember 2007

\begin{tabular}{clcc}
\hline \multirow{2}{*}{ No. } & Nama kapal & \multicolumn{2}{c}{ Hasil tangkapan penyu } \\
\cline { 3 - 4 } & & C-hook (ekor) & J-hook (ekor) \\
\hline 1. & KM. Bali Permai 169 & 2 & 3 \\
2. & KM. Samudera 31 & - & 4 \\
3. & KM. Samudera 45 & 1 & 5 \\
4. & KM. Samudera 42 & 1 & 6 \\
5. & KM. Samudera 33 & - & 4 \\
6. & KM. Samudera 30 & 1 & 5 \\
7. & KM. Samudera 37 & 1 & 4 \\
8. & KM. Sari Segara 01 & - & 6 \\
9. & KM. Maju Setia VI & 2 & 4 \\
10. & KM. Dahlia & 1 & \\
\hline
\end{tabular}

Sumber: Hasil wawancara dengan nahkoda kapal 


\section{Jenis dan Komposisi Hasil Tangkapan}

Hasil tangkapan pancing C-hook dan J-hook dari 10 kapal di perairan selatan Bali, bulan Desember 2007 terdiri atas 16 jenis jumlah 4.782 ekor, dan didominansi oleh pari (Rajidae) 1.895 ekor atau 39,63\%, ikan setan (Escoler spp.) 675 ekor atau
14,12\%, madidihang (Thunnus albacares) 472 ekor atau 9,87\%, bawal (Angel fish) 400 ekor atau 8,36\%, tuna mata besar (Thunnus obesus) 345 ekor atau 7,21\%, albakora (Albacore tuna) 236 ekor atau 4,94\%, dan cakalang (Katsuwonus pelamis) 225 ekor atau $4,70 \%$ (Tabel 4 dan 5 ).

Tabel 4. Komposisi hasil tangkapan pancing C-hook dan J-hook dari 10 kapal di perairan selatan Bali, bulan Desember 2007

\begin{tabular}{rlcc}
\hline No. & \multicolumn{1}{c}{ Jenis ikan } & Hasil (ekor) & Persentase (\%) \\
\hline 1. & Tuna mata besar (Thunnus obesus) & 345 & 7,21 \\
2. & Madidihang (Thunnus albacares) & 472 & 9,87 \\
3. & Tuna sirip biru selatan (Southern bluefin tuna) & 15 & 0,31 \\
4. & Albakora (Albacore tuna) & 236 & 4,94 \\
5. & Abuabu (longtail tuna) & 89 & 1,86 \\
6. & Cakalang (Katsuwonus pelamis) & 225 & 4,70 \\
7. & Ikan pedang (Broadbill swordfish) & 35 & 0,73 \\
8. & Setuhuk loreng (Striped marlin) & 27 & 0,56 \\
9. & Layaran (Indo-Pasific sailfish) & 14 & 0,29 \\
10. & Cucut (Requiem shark sp.) & 65 & 1,36 \\
11. & Pari (Rajidae) & 1.895 & 39,63 \\
12. & Bawal (Angel fish) & 400 & 8,36 \\
13. & Lemadang (Common dolfinfish) & 55 & 1,150 \\
14. & lkan setan (Escoler spp.) & 675 & 14,12 \\
15. & Layur (Trichiurus sp.) & 234 & 4,89 \\
16. & Penyu hijau (Chelonia mydas) & 55 & 1,150 \\
\hline
\end{tabular}

Sumber: Hasil wawancara dengan nahkoda kapal

Tabel 5 .

Laju tangkap (hook rate) 10 kapal rawai tuna di perairan selatan Bali, bulan Desember 2007

\begin{tabular}{clccccc}
\hline No. & \multicolumn{1}{c}{ Nama kapal } & $\begin{array}{c}\text { Jumlah pancing } \\
\text { (bh) }\end{array}$ & $\begin{array}{c}\text { Lama di laut } \\
\text { (hari) }\end{array}$ & $\begin{array}{c}\text { Jumlah setting } \\
\text { (kali) }\end{array}$ & $\begin{array}{c}\text { Hasil } \\
\text { (ekor) }\end{array}$ & Hook rate \\
\hline 1. & KM. Bali Permai 169 & 1.200 & 134 & 112 & 1.353 & 1,45 \\
2. & KM. Samudera 31 & 1.500 & 24 & 16 & 343 & 3,21 \\
3. & KM. Samudera 45 & 1.500 & 36 & 22 & 347 & 2,36 \\
4. & KM. Samudera 42 & 1.500 & 36 & 22 & 211 & 1,44 \\
5. & KM. Samudera 33 & 1.500 & 24 & 16 & 184 & 1,73 \\
6. & KM. Samudera 30 & 1.200 & 36 & 22 & 139 & 0,76 \\
7. & KM. Samudera 37 & 1.300 & 26 & 22 & 453 & 2,68 \\
8. & KM. Sari Segara 01 & 1.300 & 90 & 76 & 869 & 1,49 \\
9. & KM. Maju Setia VI & 1.200 & 90 & 76 & 528 & 0,83 \\
10. KM. Dahlia & 1.500 & 90 & 76 & 355 & 0,70 \\
\hline
\end{tabular}

\section{Laju Tangkap}

Hasil tangkapan pancing $C$-hook dan J-hook dari 10 kapal di perairan selatan Bali, bulan Desember 2007 dengan hasil tangkapan 4.782 ekor dengan ratarata 46 kali setting jumlah mata pancing 1.370 buah. Dengan demikian, laju tangkap 14,24 atau rata-rata 1,42 per 100 mata pancing. Laju tangkap tertinggi pada kapal ke-2 343 ekor dengan jumlah mata pancing 1.500 buah atau dengan laju tangkap 3,21 per 100 mata pancing. Laju tangkap terendah pada kapal ke10355 ekor dengan jumlah mata pancing 1.500 buah atau dengan laju tangkap 0,70 per 100 mata pancing (Tabel 5).

\section{Ukuran Ikan}

Contoh ukuran panjang dan bobot cakalang dapat diukur 27 ekor, dengan kisaran 49,0-58,5 cm, dengan bobot 1,9-2,9 kg, madidihang dapat diukur 27 ekor, dengan kisaran $117-155 \mathrm{~cm}$, dengan bobot $25-55 \mathrm{~kg}$, dan tuna mata besar dapat diukur 27 ekor, dengan kisaran $113-163 \mathrm{~cm}$, dengan bobot $28-77 \mathrm{~kg}$ (Tabel $6)$.

\section{KESIMPULAN}

1. Hasil tangkapan pancing lingkar (circle hook) lebih unggul dalam menangkap tuna $5-10 \%$ atau rata- 
Tabel 6. Ukuran panjang dan bobot ikan hasil tangkapan pancing C-hook dan J-hook dari 10 kapal di perairan selatan Bali, bulan Desember 2007

Jenis ikan: Tuna mata besar (T. obesus)

\begin{tabular}{ccccccccc}
\hline No. & FL (cm) & Bobot $(\mathbf{k g})$ & No. & FL (cm) & Bobot (kg) & No. & FL (cm) & Bobot (kg) \\
\hline 1. & 163 & 77 & 10. & 154 & 50 & 19. & 141 & 44 \\
2. & 135 & 41 & 11. & 135 & 37 & 20. & 121 & 29 \\
3. & 131 & 39 & 12. & 127 & 35 & 21. & 147 & 46 \\
4. & 119 & 28 & 13. & 149 & 69 & 22. & 126 & 30 \\
5. & 137 & 52 & 14. & 151 & 72 & 23. & 126 & 33 \\
6. & 156 & 69 & 15. & 113 & 36 & 24. & 144 & 50 \\
7. & 150 & 57 & 16. & 120 & 38 & 25. & 148 & 48 \\
8. & 140 & 43 & 17. & 151 & 56 & 26. & 139 & 42 \\
9. & 142 & 42 & 18. & 128 & 35 & 27. & 151 & 56 \\
\hline
\end{tabular}

Jenis ikan: Madidihang (T. albacares)

\begin{tabular}{ccccccccc}
\hline No. & FL $(\mathbf{c m})$ & Bobot $(\mathbf{k g})$ & No. & FL $(\mathbf{c m})$ & Bobot $(\mathbf{k g})$ & No. & FL $(\mathbf{c m})$ & Bobot $(\mathbf{k g})$ \\
\hline 1. & 144 & 46 & 10. & 118 & 25 & 19. & 128 & 34 \\
2. & 143 & 44 & 11. & 143 & 44 & 20. & 121 & 27 \\
3. & 144 & 46 & 12. & 144 & 46 & 21. & 143 & 44 \\
4. & 147 & 48 & 13. & 147 & 48 & 22. & 144 & 46 \\
5. & 139 & 42 & 14. & 133 & 38 & 23. & 147 & 48 \\
6. & 136 & 36 & 15. & 139 & 42 & 24. & 128 & 34 \\
7. & 117 & 25 & 16. & 136 & 36 & 25. & 138 & 38 \\
8. & 155 & 55 & 17. & 155 & 55 & 26. & 134 & 38 \\
9. & 147 & 47 & 18. & 147 & 47 & 27. & 147 & 48 \\
\hline
\end{tabular}

Jenis ikan: Cakalang (K. pelamis)

\begin{tabular}{ccccccccc}
\hline No. & FL (cm) & Bobot (kg) & No. & FL (cm) & Bobot $(\mathbf{k g})$ & No. & FL (cm) & Bobot (kg) \\
\hline 1. & 51,5 & 2,2 & 10. & 55,5 & 2,4 & 19. & 57,5 & 2,8 \\
2. & 50,0 & 1,9 & 11. & 58,5 & 2,9 & 20. & 55,5 & 2,4 \\
3. & 50,0 & 1,9 & 12. & 58,0 & 2,9 & 21. & 55,5 & 2,4 \\
4. & 51,0 & 2,2 & 13. & 51,5 & 2,2 & 22. & 58,0 & 2,9 \\
5. & 50,5 & 2,0 & 14. & 58,0 & 2,9 & 23. & 49,0 & 1,9 \\
6. & 49,5 & 1,9 & 15. & 57,5 & 2,8 & 24. & 49,5 & 1,9 \\
7. & 49,0 & 1,9 & 16. & 55,5 & 2,4 & 25. & 50,0 & 1,9 \\
8. & 57,5 & 2,8 & 17. & 55,5 & 2,4 & 26. & 50,2 & 2,0 \\
9. & 55,5 & 2,4 & 18. & 58,0 & 2,9 & 27. & 51,0 & 2,2 \\
\hline
\end{tabular}

Sumber: PT. Jaya Kota dan PT. PSB Benoa Bali

rata $8,15 \%$ dari total jumlah tangkapan. Dan memberikan hasil sangat signifikan dalam mengurangi bycatch penyu dari rata-rata 10-15 ekor menjadi 2-5 ekor atau mengurangi $67,27 \%$ setiap 40 hari penangkapan.

2. Komposiosi hasil tangkapan pancing $C$-hook dan J-hook, bulan Desember 2007 terdiri atas 15 jenis yaitu pari (Rajidae) 1.895 ekor atau 39,63\%, ikan setan (Escoler spp.) atau 14,12\%, madidihang (Thunnus albacares) atau 9,87\%, tuna mata besar
(Thunnus obesus ) 345 ekor atau $7,21 \%$, albakora (Albacore tuna) 4,94\%, dan cakalang (Katsuwonus pelamis) 225 ekor atau $4,70 \%$.

3. Laju tangkap kedua jenis pancing ( $C$-hook dan $J$ hook) yang dioperasikan secara bersama di perairan selatan Bali, bulan Desember 2007 ratarata 1,42. 


\section{UCAPAN TERIMA KASIH}

Penulis menghaturkan terima kasih sebesarbesarnya pada Prof. Dr. I.Gede Sedana Merta, M.Sc., dan Dr. Wijopriono, M.Sc. yang telah memberikan saran dan koreksinya, juga pada pengetik naskah, dan penerbit sehingga dapat terlaksananya tulisan ini.

\section{DAFTAR PUSTAKA}

IATTC. 1999. Assessment of yellow fin tuna eastern Pasific Ocean. Background Paper 2. 63 $3^{\text {rd }}$ Meeting of the IATTC. 8-10 June, 1999. IATTC. La Jolla. CA.

Mertha, I. G. S. 2004. Laporan Akhir Tahun 2004 (tidak diterbitkan). Balai Riset Perikanan Laut. Jakarta. 